\title{
Intention to donate blood among the eligible population in Mekelle City, Northern Ethiopia: Using the theory of planned behavior
}

\author{
Gebremeskel Mirutse ${ }^{1,}$, Girmatsion Fisseha ${ }^{1}$, Lakew Abebe ${ }^{2}$, Zewda Birhanu ${ }^{2}$, \\ Mussie Alemayehu ${ }^{1}$ \\ ${ }^{1}$ School of Public Health, College Of Health Science, Mekelle University, Mekelle, Ethiopia \\ ${ }^{2}$ Department of Health Education and Behavioral Science, College of Public Health and Medical Sciences, Jimma University, Jimma, \\ Ethiopia
}

\section{Email address:}

gebrameskelmirutse@yahoo.com (G. Mirutse), lakewterfie@yahoo.com (L. Abebe), zbkoricha@yahoo.com (Z. Birhanu), girmaf4@yahoo.com (G. Fisseha), mossalex75@gmail.com (M. Alemayehu)

\section{To cite this article:}

Gebremeskel Mirutse, Girmatsion Fisseha, Lakew Abebe, Zewda Birhanu, Mussie Alemayehu. Intention to Donate Blood among the Eligible Population in Mekelle City, Northern Ethiopia: Using the Theory of Planned Behavior. American Journal of Health Research Vol. 2, No. 4, 2014, pp. 158-163. doi: 10.11648/j.ajhr.20140204.19

\begin{abstract}
Introduction: Millions of lives are saved each year through blood transfusions. However, in most developing countries, including in Ethiopia people's still die due to inadequate supply of blood and blood products. In addition, the intention of the adult population toward blood donation is poorly assessed in Ethiopia. Thus, the aim of this study is to assess the intention and factors influencing to donate blood in Northern Ethiopia. Methods: Community based cross sectional study was conducted among the dwellers of the Mekelle town from March 1 to 25/2010. Data were collected from 768 randomly selected individuals who were eligible for blood donation. Theory of planned Behavior model was employed. Chi-square test, Correlation and Hierarchical regression analysis were employed to measure association and identify predictor variables of the behavioral intention to donate blood. Result: The overall mean of participants' intention to donate blood voluntarily over the next six months is below neutral, that is 2.74 with $(\mathrm{SD} \pm 1 \cdot 012)$. Half of the respondents have a low knowledge about blood donation and majority (88\%) did not have a history of blood donation. The variables explaining $12.7 \%$ of the variance of intention to donate blood were: knowledge $(\beta=0.277 ; \mathrm{P}<0 \cdot 0001)$, subjective norm $(\beta=0.039 ; \mathrm{P}<0 \cdot 0001)$, and attitude $(\beta$ $=0.025 ; \mathrm{P}<0.0001)$. Conclusion: People's intention to donate blood is low. Knowledge, attitude and subjective norms were main predictors of blood donation. Therefore, blood collectors should do periodic community sensitization to upgrade knowledge and create a positive attitude towards voluntary blood donation.
\end{abstract}

Keywords: Intention, Blood Donation, Eligible Population, Mekelle, Ethiopia

\section{Introduction}

Millions of lives lost each year due to lack of blood and blood products for transfusions, and most of them happen in developing countries [1].

Quarter million maternal death in the world and $15 \%$ of child mortality in Africa was due to obstetric bleeding and anemia, respectively, in which blood transfusion is always required [2]. However, annually 81 million units of blood are collected all over the world. Despite of this fact, only 27 million are collected in low- and middle-income countries, whereby $82 \%$ of the world's population lives [3].
In Sub-Saharan Africa (SSA) out of the estimated need of 18 million units of safe blood per year, merely about $15 \%$ were collected [2]. Ethiopia is the second most populous country in the continent, with an estimated population of 84 million [4]; a country with high maternal mortality $676 / 100,000$ [5] and high motor accident (among ten top countries in the world) and with a large non immune population for malaria. However, only 24,000 units were collected in 2004 (i.e. 0.3 units/1000 people) and of these $71 \%$ were collected from Addis Ababa [2]. 
There has been gross inadequacy and in-equitability in access to blood safety by the population, particularly in the regions. A very large proportion of the potentially eligible population, does not actively donate blood, and there is a need to develop better strategies to access this huge donor pool. In order to develop an effective strategy, it is critical to have a clear understanding of factors that influence people not to donate blood. Therefore, the aim of this study is to assess the level of intention of the eligible population to donate blood voluntarily. A number of psychological theories have been developed in an attempt to identify the range of issues influencing the donation intention [6] among these; theory of planned behavior model possesses consistent, predictive success and has been applied in the current research.

\section{Methods}

\subsection{Study Population and Area}

This study was conducted in Mekelle City among the 768 adult population aged 18-60 years old from March $1-25,2010$. Mekelle is the capital of Tigray region found in the northern part of Ethiopia with an estimated total population of 270,000. The town has three hospitals, seven health centers and one standard blood bank [4].

\subsection{Study Design and Sample}

A community based cross sectional study design was used. Participants were selected using the multi stage sampling technique. From a total of 62 sub districts in the town, 12 sub districts were selected by lottery method. Based on the available number of houses in each kebele, the total sample was shared using a proportion to size allocation. An eligible individual aged 18-60 years old in the household was randomly selected. When the person in the specified age is not found in the house, the next nearest household was included in the survey.

\subsection{Measurement}

Interviewer guided structured questionnaire was used to collect the data at each selected household. The tools were developed after reviewing of relevant literatures [6-8] and adapted to the context of the study area. The questionnaire was prepared on uni-polar Likert scale, where respondents were asked to indicate how strongly agrees or disagrees. In addition, Cronbach's alpha was calculated to test the reliability of the tools which was 0.8 . The questionnaire for this study consists of 53 items separated into six domains. The outcome of interest, the intention was measured by considering the extent of individuals to donate blood in the coming six months and it was assessed using three items psychological variables (attitude, subjective norm and perceived behavioral control). The measuring scales ranged from very unlikely (1) to very likely (5) and the average of the sum of the three items was taken as the intention score. Using the mean score intention was categorized in two, highly intenders and low intenders.

\subsection{Data Processing and Analysis}

Data were entered into SPSS, Version 16.0. After observing the distribution of the data a descriptive analysis (means, standard deviation) was done on all the psychosocial variables. The relationship of external variables and donations intention were described using chi-square tests and Hierarchical multiple regressions. This was carried out to identify predictor variable of intention to donate blood. The psychosocial variables were entered in the first step, socio-demographic variables on the second step and the experience of giving blood were entered in the third step, after each step the variables not reaching the $\mathrm{P}>0.05$ level of significance was eliminated from the subsequent steps.

\subsection{Ethical Considerations}

Jimma university ethical committee and regional health bureau of Tigray have approved this study project. After explaining the aim of the study and its confidentiality, verbal consent was obtained from the participants.

\section{Result}

\subsection{Socio Demography Characteristics of Respondent}

Table 1. Socio-demographic characteristics study participants, Mekelle City, Ethiopia, $2010(n=735)$

\begin{tabular}{|c|c|c|}
\hline Socio-demographic Variable & Frequency & $\%$ \\
\hline \multicolumn{3}{|l|}{ Sex of respondent } \\
\hline - $\quad$ Female & 382 & 52 \\
\hline Male & 353 & 48 \\
\hline \multicolumn{3}{|l|}{ Religion of respondent } \\
\hline - $\quad$ Orthodox & 631 & 85.9 \\
\hline Islam & 77 & 10.5 \\
\hline Protestant/ Catholic & 24 & 3.3 \\
\hline - $\quad$ Others & 3 & 0.4 \\
\hline \multicolumn{3}{|l|}{ Education status } \\
\hline - $\quad$ Notable read and write & 103 & 14 \\
\hline Primary & 55 & 7.5 \\
\hline Secondary & 347 & 47.2 \\
\hline Diploma & 135 & 18.4 \\
\hline Degree and above & 95 & 12.9 \\
\hline \multicolumn{3}{|l|}{ Occupation of respondent } \\
\hline - $\quad$ Private $\mathrm{B} / \mathrm{M}$ & 203 & 27.6 \\
\hline Student & 189 & 25.7 \\
\hline Governmental & 171 & 23.3 \\
\hline Daily laborer & 151 & 20.5 \\
\hline - $\quad$ Others & 21 & 2.9 \\
\hline \multicolumn{3}{|l|}{ Current marital status } \\
\hline - $\quad$ Married & 351 & 47.8 \\
\hline Single & 324 & 44.1 \\
\hline Divorced & 56 & 7.6 \\
\hline - Widowed & 4 & 0.5 \\
\hline \multicolumn{3}{|l|}{ Ethnicity of respondent } \\
\hline - $\quad$ Tigray & 702 & 95.5 \\
\hline Amhara & 17 & 2.3 \\
\hline - $\quad$ Afar & 5 & 0.7 \\
\hline Others & 11 & 1.5 \\
\hline
\end{tabular}


In this study, about 735 subjects were participated with a response rate of $95.7 \%$. Most of the participants were female $384(52 \%)$. The respondents mean age was 31.65 years old with SD $( \pm 10.06)$ and $(47.8 \%)$ were married. Most of the participants $(85.9 \%)$ were Orthodox Christians; half of the respondents had secondary school education. Of the respondents only $12 \%$ confirmed, they had given blood during their history. The donors' reason was; $10 \%$ for their family and $2 \%$ donated voluntarily during the sensitization period (Table 1).

\subsection{Knowledge on Blood Donation}

Of the total respondents the majority $627(85.5 \%)$ heard about blood donation from the popular sources of information; 292(39.7\%) of respondents reveal pamphlets as their source, $237(32.2 \%)$ respondent answer health institution/worker and the rest $86(11.7 \%)$ mention red cross as a source of information. The rest 12(1.5) mention the other sources.

Regarding knowledge of blood donation criteria half of the respondents 393 (53.5\%) knows the required age range for blood donation. About 488(66.4\%) do not know the time interval between blood donation. And, 601 (81.8\%) of respondents did not know the shelf life of collecting blood and $670(91.1 \%)$ of respondent thinks, individuals are screened for HIV before donation. Out of eight knowledge questions more than half of the respondent 380(51\%) score below 3 and categorized as low knowledge.

\subsection{Attitude}

The majority of respondents agree that blood donation can cause: anemia 325(44.2\%), fainting 335(45.6\%) and forced screening of HIV 398(54.1\%). Behavioral belief, and outcome evaluation were multiplied and the mean score was 54.67 with a standard deviation of \pm 20.25 . The composite measure of attitude indicates that only $73(10 \%)$ of the respondents had highly supportive attitudes towards blood donation, but $448(61 \%)$ and $214(29 \%)$ of the respondents had moderately supportive and unsupportive attitude towards blood donation, respectively.

\subsection{Subjective Norm}

Regarding the influence of the referent group on blood donation, nearly about 285(38.8\%) respondents agree that, family specially; their father and mother can influence their blood donation intention. Also the majority of 340(46.3\%) respondents agree that, they are loyal to their family opinion. The mean score of respondents' on importance the influence of the referent group toward blood donation was 34.4 and standard deviation of 16.39 out of 100 . After categorizing the result in three equal parts $(33.3 \%)$; the composite measure of subjective norms indicates that 381 $(51.8 \%)$ were under the group subjective norm relatively not important, 331(45.0\%) say moderately important and $23(3.1 \%)$ highly important.

\subsection{Perceived Behavioral Control}

As the subject's response, factors that frequently placed them in difficulty to donate blood (control belief) were: lack of information on blood shortage 493(67.1\%), lack of periodic sensitization $568(77.3 \%)$, did not know the place where blood donation takes place $556(75.6 \%)$. The result shows that $684(93.1 \%)$ of the respondent were under the group relatively low perceived behavioral control, 48 (6.5\%) of them were under the group moderate perceived behavioral control and $3(0.4 \%)$ of them were under the group high perceived behavioral control.

\subsection{Correlation Analyses}

As shown in Table 2, correlation analyses revealed that, except the perceived behavior control (PBC) all of the measured variables were significantly related to intentions to donate blood for the next six months (all $\mathrm{p}<$.0001). Attitude revealed the strongest positive association to intention to donate blood for the next 6 months, followed by subjective norm.

Table 2. Correlation analysis between intention, attitude, subjective norm, and perceived behavioral control in Mekelle City, Ethiopia ( $n=735)$

\begin{tabular}{|c|c|c|c|c|c|}
\hline \multicolumn{6}{|l|}{ Correlation } \\
\hline & & Intention mean & Attitude composite & Subjective norm composite & PBC composite \\
\hline \multirow{3}{*}{ Intention } & Person correlation & 1 & & & \\
\hline & Sig (2-tailed) & & & & \\
\hline & $\mathrm{N}$ & & & & \\
\hline \multirow{3}{*}{ Attitude } & Person correlation & $0.218^{* *}$ & & & \\
\hline & Sig (2-tailed) & 0.000 & & & \\
\hline & $\mathrm{N}$ & 735 & & & \\
\hline \multirow{3}{*}{ Subjective norm } & Person correlation & $0.225^{* *}$ & 0.021 & & \\
\hline & Sig (2-tailed) & 0.000 & 574 & & \\
\hline & $\mathrm{N}$ & 735 & 735 & & \\
\hline \multirow{3}{*}{$\mathrm{PBC}$} & Person correlation & -0.046 & -0.033 & -0.067 & \\
\hline & $\operatorname{Sig}(2$-tailed) & 0.218 & 0.372 & 0.068 & \\
\hline & $\mathrm{N}$ & 735 & 735 & 735 & 1 \\
\hline Correlation is sig & at at the 0.01 (2-tailed) & & & & \\
\hline
\end{tabular}




\subsection{Magnitude and Factor Associated with Having Intention to Donate Blood Voluntarily}

The participant's intention was measured using weighted mean and the overall intention to donate blood in the next six months was neutral which was $2 \cdot 74$ ( \pm SD 1.012).

Among total respondents, $37 \%$ reported a high intention ( $>$ 3 on the five-point scale) to give blood. A comparison of the profiles of respondents who had high intention 270 (37\%), with those who had low intention 465 (63\%), the following characteristics were shown group difference to donate blood among educational status $[\mathrm{x} 2=14.95, \mathrm{p}=0.011]$; occupations $[\mathrm{x} 2=12.11, \mathrm{p}<0.017]$; marital status $[\mathrm{x} 2=$ $15.39, \mathrm{p}<0.0001]$; past history of blood donation $[\mathrm{x} 2=6.03$, $\mathrm{p}=0.014]$, knowledge respondent $[\mathrm{x} 2=16.709, \mathrm{p}<0.0001]$, to donate blood on the future (Table 3 ).

Hierarchical multiple regressions were done to identify predictor variables of intention to donate blood and variables like: attitude $(\beta=0.025 ; \mathrm{P}<0.0001)$; subjective norm $(\beta=$ 0.039; $\mathrm{P}<0.0001)$, knowledge $(\beta=0.277 ; \mathrm{P}<0.0001)$ and education $(\beta=0.222 ; \mathrm{P}=0.002)$ were identified as significant predictors of intention to donate blood (Table 4).

Table 3. Association between different respondent characteristics and intention to donate blood, Mekelle City, Ethiopia, 2010 (N=735)

\begin{tabular}{|c|c|c|c|c|}
\hline \multirow{2}{*}{ Variable } & \multirow{2}{*}{$\begin{array}{l}\text { High intention } \mathrm{N}=270 \\
\text { No }(\%)\end{array}$} & \multirow{2}{*}{$\begin{array}{l}\text { Low intention } \mathrm{N}=465 \\
\text { No }(\%)\end{array}$} & \multirow{2}{*}{$\mathbf{X}^{2}$} & \multirow{2}{*}{$P_{\text {_ value }}$} \\
\hline & & & & \\
\hline \multicolumn{5}{|l|}{ Age } \\
\hline $18-28$ & $136(40.4)$ & $201(59.6)$ & & \\
\hline $29-38$ & $84(36.2)$ & $148(63.8)$ & & \\
\hline $39-48$ & $34(31.7)$ & $73(68.3)$ & & \\
\hline $49-60$ & $16(27.1)$ & $43(72.9)$ & 5.409 & 0.144 \\
\hline \multicolumn{5}{|l|}{ Marital } \\
\hline Single & $126(41.4)$ & $198(58.6)$ & & \\
\hline Married & $136(38.7)$ & $215(61.3)$ & & \\
\hline Divorced & $7(12.5)$ & $49(87.5)$ & & \\
\hline Widowed & $1(25)$ & $3(75)$ & 15.647 & 0.001 \\
\hline \multicolumn{5}{|l|}{ Education } \\
\hline Notable\& read & $22(21.3)$ & $81(78.7)$ & & \\
\hline Grade 1-4 & $20(37.3)$ & $35(62.7)$ & & \\
\hline Grade5-8 & $51(36.9)$ & $87(63.1)$ & & \\
\hline Grade 9-12 & $79(37.7)$ & $130(61.3)$ & & \\
\hline Diploma & $54(43.2)$ & $81(56.8)$ & & \\
\hline Degree and above & $44(42.6)$ & $51(57.4)$ & 14.957 & 0.011 \\
\hline \multicolumn{5}{|l|}{ Occupation } \\
\hline Student & $74(39.1)$ & $115(60.9)$ & & \\
\hline Daily laborer & $48(31.7)$ & $103(68.3)$ & & \\
\hline Private $\mathrm{B} / \mathrm{M}$ & $62(30.5)$ & $141(69.5)$ & & \\
\hline Government & $86(44.8)$ & $106(55.2)$ & 10.778 & 0.013 \\
\hline \multicolumn{5}{|l|}{ History donation } \\
\hline Yes & $44(48.4)$ & $47(51.6)$ & & \\
\hline No & $226(35.1)$ & $418(64.9)$ & 6.031 & 0.014 \\
\hline \multicolumn{5}{|l|}{ Knowledge } \\
\hline High & $94(48.9)$ & $98(51.1)$ & & \\
\hline Low & $176(32.4)$ & $367(67.6)$ & 16.71 & 0.0001 \\
\hline
\end{tabular}

Table 4. Hierarchical multiple regressions and the predictors of intention to donate blood voluntarily among the eligible population in Mekelle City, Ethiopia $2010(N=735)$

\begin{tabular}{|c|c|c|c|c|c|c|c|c|}
\hline \multirow{3}{*}{\multicolumn{2}{|c|}{ Model }} & \multicolumn{7}{|c|}{ Coefficients } \\
\hline & & \multicolumn{2}{|c|}{ Un-standardized } & \multirow{2}{*}{$\begin{array}{l}\text { Standardized } \\
\text { Beta }\end{array}$} & \multirow{2}{*}{$\mathbf{t}$} & \multirow{2}{*}{ Sig. } & \multicolumn{2}{|c|}{$95 \%$ CI for B } \\
\hline & & B & $\mathbf{S} / \mathbf{E}$ & & & & Lower & Upper \\
\hline \multirow{6}{*}{1} & (Constant) & 3.798 & 0.489 & & 7.766 & 0.000 & 2.838 & 4.759 \\
\hline & Attitude & 0.025 & 0.005 & 0.167 & 4.599 & 0.000 & 0.014 & 0.036 \\
\hline & Subjective & 0.039 & 0.006 & 0.212 & 6.110 & 0.000 & 0.027 & 0.052 \\
\hline & $\mathrm{PBC}$ & -0.006 & 0.010 & -0.020 & -.563 & 0.573 & -0.025 & 0.014 \\
\hline & Knowledge & 0.277 & 0.064 & 0.150 & 4.327 & 0.000 & 0.151 & 0.402 \\
\hline & Education & 0.222 & 0.072 & 0.112 & 3.100 & 0.002 & 0.082 & 0.363 \\
\hline
\end{tabular}




\section{Discussion}

The overall intention of respondents to donate blood voluntarily in this study was $37 \%$ and attitude, subjective norm, perceived behavioral control, education and knowledge of the participant toward blood donation were predictors of blood donation voluntarily.

The overall intention of the participant to donate blood for the next six months was low 2.74 with standard deviations of (SD \pm 1.012 ) which is consistent with a study done in Canada [6] with $2.84(\mathrm{SD} \pm 1 \cdot 16)$.

In this study, among the total respondent, $12.4 \%$ had a history of blood donation, which was lower than in a study done in Saudi Arabia (34.16\%) [8], and Canada (43.8\%) [6], this difference could be due to there is poor social marketing to ward blood donation and periodic sensitization in the study area.

In our study, eight out of ten respondents donate blood for replacement (family, paid) but only $19.8 \%$ donate voluntarily. This is far away as compared with the result of blood safety in a developed country in which $94 \%$ of blood donation are from volunteers [3]. This could be due to poor donor recruitment and retention system of the country, differences in socio economic status.

Different study revealed that blood donation is completely differing by sex. Males were more likely to donate blood more than females $[8,9]$. Our finding is also consistent with these findings in which $59.3 \%$ of the blood donator were males. This could be in congruent to cultural belief of that male are better and strong to take responsibility than female.

Knowledge of blood donation is a prerequisite to obtaining access to and provide blood voluntarily on timely and effective. And it is an important tool for avoiding fear and building positive attitude. Controlling for other variable knowledge of blood donation emerged as a statistically significant predictor of behavioral intentions to donate blood while the knowledge of respondent increases their intention to donate blood also increase at $[\mathrm{F}=5,729=22.123, \beta=$ 0.277 and $\mathrm{p}<0.001]$. This finding was consistent with study done by K.P.H. Lemmens [10]. Having low proportion of blood donation in, this could be due to the fact that half of the participants had poor knowledge about blood donation. However, this finding is higher than in study in Israel (14.5\%) [9]. This could be due to difference in accessing information, education status of the respondent, as well in Israel have better health education system than Ethiopia.

Education level of respondent emerged as a statistically significant predictor of behavioral intentions to donate blood. When comparing those intended to donate blood with those no intentions, respondents with substantial not able to read and write were 3.079 times $(p<0.0001$ : $95 \%$ C. I. ORs $=1$. 652-5.74) more likely to donate blood for the next six months than those higher classes, this is consistent with the study in Canada [6]. Thus, the probability of expressing a positive intention is weaker among more educated people. This could be due to lack of audience segmentation for providing information or applying equal motivational strategy for both educated and non educated individuals.

Personal experience with blood donation emerged as a statistically significant predictor of behavioral intentions to donate blood. Controlling for other variables in the model, when contrasting those who intended to donate blood with those who had no intention, respondents with substantial personal experience were 0.41 times $(\mathrm{p}=0.021$ : $95 \% \mathrm{C}$. I. ORs $0.377-0.924$ ) less likely to donate blood in the next six months than those with no personal experience which is similar with a study conducted by Godin et al [6]. The proportion of people with a strong intention to donate blood in the following 6 months was much higher among people who had already donated blood in their life compared to those who had not which is similar with a study by Armitage and Conner [11].

Respondents' attitude towards blood donation varied from 9 to 125 with a mean score of 54.67 and standard deviation of \pm 20.25 which is low. This is due to the majority of the participant in this study believing that blood donation causes anemia and fainting. Controlling for other variable when attitude composite regressed on the dependent variable of behavioral intention attitude was found as significant predictor of intention to donate blood this indicate as the attitude of respondent become supportive as well intention to donate blood was high at $[\mathrm{F} 5,729=22.123 \beta=0.25$ and $\mathrm{p}<0.001]$ this is similar with the finding in Canada [6], and with the theory of planed behavior when attitude become positive toward the behavior the likely hood of performing the behavior is high.

The variables explaining $12.7 \%$ of the variance of intention to donate blood were: attitude $(\beta=0.025 ; \mathrm{P}<$ $0.0001)$; subjective norm $(\beta=0.039 ; \mathrm{P}<0.0001)$ knowledge $(\beta=0.277 ; \mathrm{P}<0.0001)$ and education $(\beta=0.222 ; \mathrm{P}=0.002)$. Were significant predictor of intention among the principal determinants of intention to donate blood, the following stand out: knowledge and education, from external variable subjective norm and attitude as the most important predictor among all this is similar with study done by Mike Reid and Angela Wood (2008) and Godin etal (2005) $[6,12]$.

The simultaneous predictive power of attitudes, subjective norms and perceived behavioral control on intention in terms of the adjusted R square was 0.094 (i.e., explained only $9.4 \%$ of variance). Similar study done in Australia by Mike Reid and Angela Wood (2008) [12] the final model accounted for $26.1 \%$ of the variance in intention to donate and study done by Lemmens et al (2005) [10] theory accounted for $43 \%$ of the variance in donation intention this is higher than this study this could be due to the difference in culture and exposure, and education status of respondent, socio economic status of the respondent.

This study has assessed the level of intention. But it has certain limitation. Since it is a cross sectional study it did not show cause and effect relationship between dependent and independent variables. Beside this, the assessing the attitude, 
subjective norm and perceived behavioral control is to complex may have influence in measuring the intention can lead to over or under estimation or results. In addition; behavioral model, is not well discussed with literatures done in similar set up and Africa. So, it is important to take a consideration in interpretation of the findings.

\section{Conclusion}

This study revealed individual's intention to donate blood over the next six month is very low; above half of the respondents have low knowledge and unsupportive attitude toward blood donation. Individuals with history of blood donation and higher education do not intend to donate blood on the future. As recommendation, it is important that the regional health bureau should use Radio, TV programmes to create community awareness, increase knowledge to positively influence individual's unsupportive attitude toward blood donation. Informing audience during health education, community periodic sensitization, and addressing the place where voluntary blood donation was taken place. Educated individuals and political leaders in the region by participating in voluntary blood donation to break the poor attitude of community to ward blood donation could be some solutions. It is also important to consider blood donor workers in the blood bank centers to show good approach and provide counseling for those who donate blood on the center for replacement or voluntary.

\section{Acknowledgements}

The authors would like to thank Jimma University for financial support of this study. Our gratitude goes to supervisors, data collectors, respondents who participated in this study and friends for their contribution in accomplishment of this study.

\section{Competing Interests}

The authors declare that they have no competing interests.

\section{Authors' Contributions}

$\mathrm{GMS}^{1}$ : $\mathrm{LAT}^{2}: \mathrm{ZB}^{2}$ : has taken a principal role in the conception of ideas, developing methodologies and writing the article. $\mathrm{GMS}^{1}$ : $\mathrm{GF}^{1}$ : $\mathrm{MA}^{1}$ : were involved in data collection, analysis, and interpretation of the data and preparation of the manuscript. All authors are accepted the final manuscript.

\section{References}

[1] GDBS. (1998-1999). World Health Organization Blood Transfusion Safety 1211 Geneva 27, Switzerland http://www.who.int/bct/bts

[2] WHO African Region. (2006). Ethiopia 2006 /Regional training workshop on blood donor recruitment: pre and post donation counseling.

[3] Blood safety. (2005). A global overview fact sheet Copenhagen, 10 June 2005 (http://www.wbdd.org/index.php?id=13).

[4] Federal Democratic Republic of Ethiopia population census commission. Summary and Statistical Report of the 2007 Addis Ababa: Central Statistical Agency 2007.

[5] Centeral Statistics Agency, ICF MacroCalverton. Ethiopia Demographic and Health Survey 2011. Addis Ababa: CSA2011.

[6] Godin et al. (2005). Factors explaining the intention to give blood among the General population (C2005 Blackwell Publishing Ltd.Vox Sanguinis; 89, 140-149.

[7] Icek Ajzen. (2006). Constructing a TpB Questionnaire: Conceptual and Methodological Considerations September, 2002 (Revised January, 2006)

[8] Abdul Majeed Al-Drees et al. (2008). Attitude, belief, knowledge about blood Donation, transfusion in Saudi population ;Blood Donation, and Transfusion, January March 2008 Vol. 24 No. 1 74-79.

[9] Weinberg et al. (2008). Why would young people donate blood? A survey-based questionnaire study Journal compilation 2008 International Society of Blood Transfusion.

[10] K. P. H. Lemmens, et.al (2008) Identifying blood donors willing to help with recruitment Vox Sanguinis 95, 211-217.

[11] Armitage and Conner.(2001) Social Cognitive Determinants of Blood Donation Journal of Applied Social Psychology, 2001, 31, 7, pp. 1431-1457.

[12] Mike Reid etal. (2008) an investigation into blood donation intentions among non-donors Int. J. Non profit Volunt. Sect. Mark., February 2008. 